University of Nebraska - Lincoln

DigitalCommons@University of Nebraska - Lincoln

Effect of Increasing Corn Silage Inclusion in Finishing Diets with or without Tylosin on Performance and Liver Abscesses

Hannah C. Wilson

Levi McPhillips

Bradely M. Boyd

Andrea K. Watson

J. C. MacDonald

See next page for additional authors

Follow this and additional works at: https://digitalcommons.unl.edu/animalscinbcr

Part of the Large or Food Animal and Equine Medicine Commons, Meat Science Commons, and the Veterinary Preventive Medicine, Epidemiology, and Public Health Commons

This Article is brought to you for free and open access by the Animal Science Department at DigitalCommons@University of Nebraska - Lincoln. It has been accepted for inclusion in Nebraska Beef Cattle Reports by an authorized administrator of DigitalCommons@University of Nebraska - Lincoln. 
Authors

Hannah C. Wilson, Levi McPhillips, Bradely M. Boyd, Andrea K. Watson, J. C. MacDonald, and Galen E. Erickson 


\section{Effect of Increasing Corn Silage Inclusion in Finishing Diets with or without Tylosin on Performance and Liver Abscesses}

\author{
Hannah C. Wilson \\ Levi J. McPhillips \\ Bradley M. Boyd \\ Andrea K. Watson \\ Jim C. MacDonald \\ Galen E. Erickson
}

\section{Summary with Implications}

A finishing study was conducted to assess the impact of increasing silage inclusion in finishing diets to reduce the prevalence of liver abscesses in beef cattle. Cattle were fed two inclusions of corn silage (15 or $45 \%$ of diet dry matter), with or without tylosin for control of liver abscesses. Cattle fed 15\% corn silage had a $2 \%$ improvement in feed efficiency when tylosin was added to the diet. However, in cattle fed $45 \%$ corn silage, no improvements in feed efficiency were observed when tylosin was added to the diet. Cattle fed $15 \%$ corn silage without tylosin, had the greatest prevalence of liver abscesses (34.5\%) compared to other treatments, and abscess prevalence was decreased to $19 \%$ if tylosin was fed with 15\% corn silage. Feeding 45\% silage was effective at lowering liver abscess prevalence which was $12.4 \%$, regardless of whether tylosin was fed. Feeding corn silage at $45 \%$ of diet dry matter was as effective as feeding tylosin at controlling abscess rates. Feeding corn silage at greater inclusions decreased average daily gain but increased final body weight when fed to an equal fatness (28 days longer). Feeding elevated concentrations of corn silage in diets containing distillers grains may be a viable method to control liver abscesses without antibiotic use, but has performance implications.

\section{Introduction}

To reduce the use of antibiotics and the need for veterinary approval, there is interest in natural alternatives (additives or dietary interventions) for the prevention of

(c) The Board Regents of the University of Nebraska. All rights reserved.

Table 1. Composition (\% of diet DM) of dietary treatments fed to calf-fed steers with or without tylosin

\begin{tabular}{|c|c|c|c|c|}
\hline \multirow[b]{2}{*}{ Ingredient } & \multicolumn{4}{|c|}{ Treatment $^{1}$} \\
\hline & CS15 & CS45 & TCS15 & TCS45 \\
\hline High-moisture corn & 36.6 & 18.6 & 36.6 & 18.6 \\
\hline Dry-rolled corn & 24.4 & 12.4 & 24.4 & 12.4 \\
\hline Corn silage & 15 & 45 & 15 & 45 \\
\hline Wet distillers grains & 20 & 20 & 20 & 20 \\
\hline Supplement ${ }^{2}$ & 4 & 4 & 4 & 4 \\
\hline \multicolumn{5}{|c|}{$\begin{array}{l}\text { Treatments included CS15: Corn silage included at 15\% of diet DM without tylosin; CS45: Corn silage included at 15\% of diet } \\
\text { DM without tylosin; TCS15: Corn silage included at 15\% of diet DM with tylosin; TCS45: Corn silage included at 15\% of diet } \\
\text { DM with tylosin. }\end{array}$} \\
\hline \multicolumn{5}{|c|}{$\begin{array}{l}{ }^{2} \text { Supplement included } 0.5 \% \text { urea and Rumensin (Elanco Animal Health) at } 30 \mathrm{~g} \text { / ton DM. If tylosin was included, it was formu- } \\
\text { lated to supply Tylan (Elanco Animal Health) at } 8.8 \mathrm{~g} / \text { ton DM. FD \& C Blue Dye: water-soluble artificial blue dye allowed by } \\
\text { the FDA for use in foods; was used to identify correct supplement delivery. Vitamin A-D-E premix contained } 30,000 \mathrm{IU} \text { of vit } \\
\text { A, } 6,000 \mathrm{IU} \text { of vit D, } 7.5 \mathrm{IU} \text { of vit E per gram. Trace mineral premix contained } 6 \% \mathrm{Zn}, 5.0 \% \mathrm{Fe}, 4.0 \% \mathrm{Mn}, 2.00 \% \mathrm{Cu}, 0.29 \% \mathrm{Mg} \text {, } \\
0.2 \% \mathrm{I} \text {, and } 0.05 \% \mathrm{Co} \text {. }\end{array}$} \\
\hline
\end{tabular}

liver abscesses, but these alternatives must be efficacious. Feeding high concentrations of corn silage can be economical, efficient, and potentially decrease the risk of liver abscesses in cattle. Increasing corn silage by replacing corn grain increased feed conversion $(\mathrm{F}: \mathrm{G})$ and reduced average daily gain (ADG) in cattle but can still be economical. The main objective of this project was to determine if an increase in corn silage in the diet would decrease the prevalence of liver abscesses without the inclusion of tylosin.

\section{Procedure}

Corn silage was harvested at the Eastern Nebraska Research and Extension Center (ENREC) near Mead, Nebraska, between August 27 and 31, and on September 10, 2018. Corn silage harvest was initiated when the field was approximately $3 / 4$ milkline and 37\% DM. Silages were stored in sealed silage bags and opened after 21 days.

Crossbred calf-fed steers ( $\mathrm{n}=640$; initial body weight [BW] $586 \pm 30 \mathrm{lbs}$ ) were sorted into $2 \mathrm{BW}$ blocks and assigned randomly to one of 32 pens (20 steers/pen). The light block included 2 replications, and the heavy block included 6 replications per treatment. Cattle were started at two time points starting on November 20 for block 1 and November 30 for block 2. All steers were weighed on 2 consecutive days after limit-feeding a common diet of $50 \%$ alfalfa hay and $50 \%$ Sweet Bran at $2 \%$ of BW for 5 days.

Treatments were arranged as a $2 \times 2$ factorial, that consisted of two inclusions of corn silage ( 15 or $45 \%$ ), with (TCS15, TCS45) or without tylosin (CS15, CS45; Table 1). All steers were fed monensin (Rumensin, Elanco Animal Health) at 30 $\mathrm{g} /$ ton of DM and tylosin (Tylan; Elanco Animal Health) was included at $8.8 \mathrm{~g} / \mathrm{ton}$ of DM for the two treatments including tylosin. Feed was delivered once daily.

Steers were implanted with a Revalor-IS (Merck Animal Health) on d 1 and then re-implanted with a Revalor-200 (Merck Animal Health) on day 75 and 85 for blocks 1 and 2, respectively. Cattle fed $15 \%$ corn silage were shipped on May $28^{\text {th }}$ after 185 days on feed. To achieve similar fatness, cattle fed $45 \%$ corn silage were shipped 4 weeks later, on June $25^{\text {th }}$ after 213 days on feed.

On the day of harvest, hot carcass weight (HCW) was recorded, and carcassadjusted final BW was used to determine average daily gain (ADG) and feed conversion (F:G). On the day of harvest, liver 
Table 2. Simple effects for carcass adjusted performance of cattle fed 15 or $45 \%$ corn silage with or without tylosin

\begin{tabular}{|c|c|c|c|c|c|c|c|c|}
\hline & \multicolumn{4}{|c|}{ Treatment $^{1}$} & \multirow[b]{3}{*}{ SEM } & \multirow{2}{*}{\multicolumn{3}{|c|}{$P$-value }} \\
\hline & \multicolumn{2}{|c|}{ - Tylosin } & \multicolumn{2}{|c|}{+ Tylosin } & & & & \\
\hline & CS15 & CS45 & TCS15 & TCS45 & & $\begin{array}{c}\text { Tylosin } \times \\
\text { Silage }\end{array}$ & Tylosin & Silage \\
\hline Days on Feed & 185 & 213 & 185 & 213 & - & - & - & - \\
\hline Initial BW, lbs & 646 & 646 & 645 & 646 & 10.7 & 0.97 & 0.94 & 0.97 \\
\hline Live final BW, lbs & 1282 & 1336 & 1294 & 1339 & 14.6 & 0.77 & 0.60 & $<0.01$ \\
\hline \multicolumn{9}{|l|}{ Carcass Adjusted Performance } \\
\hline Final BW, lbs & 1281 & 1336 & 1296 & 1328 & 16.1 & 0.51 & 0.82 & 0.01 \\
\hline DMI, lbs / d & 21.7 & 23.1 & 21.7 & 23.1 & 0.25 & 0.94 & 0.86 & $<0.01$ \\
\hline ADG & 3.43 & 3.24 & 3.52 & 3.21 & 0.046 & 0.21 & 0.55 & $<0.01$ \\
\hline $\mathrm{G}: \mathrm{F}$ & $0.158^{\mathrm{b}}$ & $0.140^{c}$ & $0.162^{\mathrm{a}}$ & $0.139^{c}$ & 0.0015 & 0.10 & 0.27 & $<0.01$ \\
\hline$F: G$ & 6.34 & 7.15 & 6.16 & 7.21 & - & - & - & - \\
\hline \multicolumn{9}{|l|}{ Carcass Characteristics ${ }^{3}$} \\
\hline HCW, lbs & 807 & 841 & 816 & 837 & 10.2 & 0.53 & 0.84 & 0.01 \\
\hline LM area, in ${ }^{2}$ & 13.9 & 13.8 & 13.9 & 13.6 & 0.14 & 0.53 & 0.53 & 0.18 \\
\hline $12^{\text {th }}$ rib fat, in & 0.48 & 0.49 & 0.46 & 0.49 & 0.014 & 0.50 & 0.69 & 0.10 \\
\hline Marbling $^{4}$ & 456 & 446 & 440 & 445 & 7.14 & 0.33 & 0.25 & 0.69 \\
\hline Calculated Yield Grade ${ }^{5}$ & 2.82 & 3.01 & 2.83 & 3.07 & 0.05 & 0.60 & 0.54 & $<0.01$ \\
\hline Quality Grade & 3.07 & 3.13 & 3.2 & 3.14 & 0.06 & 0.30 & 0.23 & 0.97 \\
\hline Dressing, \% & 63.2 & 63.2 & 63.3 & 62.7 & 0.14 & 0.20 & 0.33 & 0.15 \\
\hline Liver abscesses ${ }^{6}$ & $34.5^{\mathrm{a}}$ & $12.0^{\mathrm{b}}$ & $19.2^{\mathrm{b}}$ & $12.7^{\mathrm{b}}$ & 5.55 & 0.05 & 0.09 & $<0.01$ \\
\hline
\end{tabular}

${ }^{1}$ Treatments included CS15: Corn silage included at 15\% of diet DM without tylosin; CS45: Corn silage included at 15\% of diet DM without tylosin; TCS15: Corn silage included at 15\% with tylosin; TCS45: Corn silage included at $15 \%$ with tylosin.

${ }^{2}$ Tylosin $\times$ CS $=P$-value for the interaction between corn silage inclusion and tylosin inclusions; tylosin $=P$-value for the main effect of tylosin inclusion; $\mathrm{CS}=P$-value for the main effect of corn silage inclusion.

${ }^{3}$ Calculated on a carcass-adjusted basis using a common dressing percentage (63\%).

${ }^{4}$ Marbling Score $300=$ Slight, $400=$ Small, $500=$ Modest, etc.

${ }^{5}$ Calculated as $2.5+(2.5 \times 12$ th rib fat $)+(0.2 \times 2.0[\mathrm{KPH}])+(0.0038 \times \mathrm{HCW})-(0.32 \times \mathrm{LM}$ area $)$

${ }^{6}$ Calculated as a percent of total steers; dead steers removed

scores were recorded immediately following evisceration. The scoring system used was as follows: 0, no liver abscesses; A-, one or very few small abscesses; A, 1 large abscess or a few small abscesses; A+, many large abscesses. Carcass characteristics, recorded after a 48-h chill, included marbling score, $12^{\text {th }}$ rib fat thickness, and LM area.

Data were analyzed using the PROC MIXED procedures of SAS as a randomized block design with pen as the experimental unit and block as a fixed effect. The experiment was analyzed as a $2 \times 2$ factorial with two inclusions of corn silage (15 or 45) and with or without tylosin. Post-trial, hot carcass weight was analyzed within liver abscess severity category. Liver abscess category, treatment, and the interaction between liver abscess category and treatment were used as fixed effects. An economic analysis was reported in 2021 Nebraska Beef Cattle Report, pp. 69-71.

\section{Results}

By design, all cattle were fed to a similar $12^{\text {th }}$ rib fat thickness $(P=0.10)$ to ensure equal degree of finish when comparing performance and carcass characteristics. Cattle fed $45 \%$ corn silage were fed for 213 days and $15 \%$ corn silage were fed for 185 days (Table 2).

There was an interaction for feed conversion $(P=0.10)$. Cattle fed 15CS with tylosin (T15CS) had the lowest F:G, 15\% corn silage without tylosin (15CS) was intermediate, and both $45 \%$ corn silage with and without tylosin (45CS and T45CS) had the poorest feed conversion. Cattle fed $15 \mathrm{CS}$ had a $3 \%$ decrease in F:G when tylosin was added to the diet. However, in cattle fed 45CS, no improvements in F:G were observed when tylosin was added to the diet.

There were no interactions for live final BW, carcass-adjusted final BW, HCW, dry matter intake (DMI) or average daily gain (ADG; $P \geq 0.21$ ), so main effects of silage inclusion or tylosin inclusion will be discussed. Cattle fed $45 \%$ corn silage had greater $(P \leq 0.01)$ live final BW, carcass- 
Table 3. Hot carcass distributions relationship with categorical liver abscess score

\begin{tabular}{|c|c|c|c|c|c|c|}
\hline \multirow[b]{2}{*}{ Item } & \multicolumn{4}{|c|}{ Liver score } & \multirow[b]{2}{*}{ SEM } & \multirow[b]{2}{*}{$P$-value } \\
\hline & 0 & A- & A & $\mathrm{A}+$ & & \\
\hline Cattle, $n$ & 501 & 50 & 26 & 49 & - & - \\
\hline \multicolumn{7}{|l|}{ Hot Carcass Weight } \\
\hline Minimum & 610 & 678 & 693 & 601 & - & - \\
\hline Maximum & 1054 & 935 & 924 & 924 & - & - \\
\hline Standard Deviation & 59.6 & 59.0 & 51.5 & 75.0 & - & - \\
\hline Average & 829 & 814 & 825 & 785 & 32.3 & $<0.01$ \\
\hline
\end{tabular}

adjusted final body weight, and HCW compared to cattle fed $15 \%$ corn silage due to the greater days fed to equalize fatness. Cattle fed $45 \%$ corn silage had greater DMI but lower ADG compared to cattle fed 15\% corn silage $(P \leq 0.01)$. There was no effect of silage inclusion on longissimus muscle area (LM area), marbling, dressing percentage, or quality grade. Calculated yield grade was greater for cattle fed $45 \%$ corn silage $(P<$ 0.01 ). Additionally, there was a significant shift in USDA YG distributions between 15 or $45 \%$ silage treatment with cattle fed $45 \%$ silage being slightly fatter $(P=0.10)$ with greater USDA YG $(P<0.01)$. There was no effect of tylosin for live or carcass-adjusted final BW, or HCW. Additionally, tylosin did not affect DMI or ADG $(P \geq 0.55)$.

Overall, in this study liver abscess prevalence ranged from 12.0 to $34.5 \%$. There was an interaction for liver abscesses, where cattle fed CS15 (no tylosin) had the greatest prevalence of liver abscesses (34.5\%) compared to all other treatments $(P=0.05$; Table 2). Cattle fed 15CS benefited from the addition of tylosin in the diet by reducing the prevalence of liver abscesses from 34.5\% to $19.2 \%$ ( $44.3 \%$ reduction). However, no differences in prevalence were observed when cattle were fed $45 \%$ corn silage with tylosin (12.7\%) or without tylosin (12.0\%).

Additionally, there was a tendency for an interaction $(P=0.11)$ between corn silage and tylosin inclusion for the distribution of abscess severity (data not shown). In addition to having the greatest prevalence of liver abscesses, cattle fed 15CS (no tylosin) also had the greatest number of severe abscesses, with $27.8 \% \mathrm{~A}$ or A+ liver abscesses. Severity was lessened (fewer A+) when cattle were fed T15CS (with tylosin). Cattle fed 45CS and T45CS had comparable distributions in severe liver abscesses. These data suggest that increasing corn silage in the diet had similar effects to adding tylosin to $15 \%$ corn silage diets. Additionally, adding tylosin to a $45 \%$ corn silage diet had no additional benefits and did not reduce liver abscesses further.

An exploratory analysis was conducted to determine hot carcass distributions relationship with categorical liver abscess score (Table 3). Hot carcass weight was significantly reduced when cattle were scored with A+ livers (785 lbs), compared to other severity categories (A-, 814 lbs; A, $825 \mathrm{lbs}$ ) and cattle with no abscesses (829 lbs). Cattle with A+ abscesses had the greatest standard deviation with the lowest minimum and maximum carcass weights. The distributions of hot carcass weight are similar for steers with livers that were scored 0, A-, or A. However, when steers had A+ livers the distribution of hot carcass weights for those animals shifted to the left, leading to an overall lower average, but an increase in standard deviation across the mean. Additionally, $50 \%$ of steers with an A+ liver score had a hot carcass weight of $800 \mathrm{lbs}$ or lighter. However, steers with scores of 0 , A, or A- were heavier with only an average of $15 \%$ of cattle with hot carcass weights of $800 \mathrm{lbs}$ or lighter. Only severe abscesses $(\mathrm{A}+)$ reduced hot carcass weight in this study. Because the trial was not able to measure live final body weight on individual cattle, these losses in hot carcass weight cannot be directly attributed to either decreased live performance or additional carcass trim at the time of harvest.

\section{Conclusion}

Cattle fed $45 \%$ corn silage had poorer gain and conversions but greater final body weights when finished to a common fat thickness compared with cattle fed 15\% corn silage. Feeding tylosin in diets containing $85 \%$ concentrate led to a decrease in prevalence of liver abscesses. However, feeding corn silage at $45 \%$ also decreased the prevalence of liver abscesses with or without the inclusion of tylosin.

Hannah C. Wilson, research technician

Bradley M. Boyd, research technician

Levi J. Hilscher, research technician

Zachary E. Carlson, research technician

Andrea K. Watson, assistant professor

Jim C. MacDonald, professor

Galen E. Erickson, professor, Animal Science, University of Nebraska-Lincoln 